\title{
Bolivia: de su «era del gas» a... ¿qué?
}

\author{
Bolivia: from gas to... what?
}

\author{
Carlos Alberto López
}

\section{Resumen}

Es poco probable que en las actuales condiciones políticas y sociales en Bolivia se pueda dar una reactivación real de su industria petrolera. La falta de competitividad del régimen tributario boliviano y el poco disimulado antagonismo hacia la inversión extranjera hace que ésta fluya preferentemente a otros destinos menos volátiles en la región. Y la falta de competitividad relativa del precio del gas boliviano, hace que Brasil, Argentina y Chile estén hoy en proceso de comprometer sus mercados a la importación de LNG que, aunque a precios superiores, evita cualquier dependencia de Bolivia y asegura un abastecimiento confiable, flexible y alejado de los vaivenes y de la incertidumbre hoy predominantes en el país. Las grandes inversiones necesarias no solo para incrementar la capacidad de producción requerida en 2010 sino simplemente para sustentar los actuales volúmenes de producción, y la ausencia, por ahora, de cualquier indicio concreto de reactivación de las actividades de exploración y desarrollo en el país hacen prever que Bolivia puede aún no haber enfrentado los momentos más incómodos y difíciles de su coyuntura petrolera.

Palabras Claves: Gas natural, reservas, control estatal, inserción capacidad productiva.

Consultor en la industria del gas y el petróleo en Bolivia y Cono Sur (cal@entelnet.bo).

Recibido el 20 de noviembre de 2007; aceptado el 5 de enero de 2008. 


\section{Abstract}

It is unlikely that in the present political and social conditions in Bolivia a real reactivation of its oil industry will materialize any time soon. The lack of competitiveness of Bolivia's fiscal regime and the government's undisguised antagonism towards foreign investment have pushed capital flows to seek other, less volatile, destinations in the region. And the lack of relative competitiveness of the price of Bolivian gas, have pushed Brazil, Argentina and Chile to commit their markets to imported LNG that, even if more costly, avoids any dependence on Bolivia and ensures a reliable, flexible and stable supply that steers clear of the prevailin swings and uncertainties in the country. The massive investments necessary not only to increase the productive capacity required in 2010 but, simply, to sustain current production volumes, and the absence, so far, of any concrete evidence of reactivation in exploration and development activities in the country indicate that Bolivia's oil industry may not yet have faced its most unpleasant and difficult moments.

KEY WORDS: Natural gas, reserves, state control, investment productive capacity. 
Hace solo cinco años, Bolivia enfrentaba una situación en la que era víctima de su propio éxito. En efecto solo los cinco años anteriores había pasado de una posición irrelevante en términos energéticos regionales y de enfrentar, en 1999, el vencimiento de su único contrato de exportación de gas a la Argentina, del que por casi dos décadas y media había dependido para sustentar su industria petrolera y su economía, a una situación que se llegó a llamar la «era del gas» boliviano, en la que tras atraer ingentes inversiones e incrementar sus reservas en casi un $900 \%$ y con el contrato de exportación a Brasil. De los 54.9 TCFs de reservas probadas y probables descubiertos en ese período, Bolivia tenía colocados unicamente 7.8 TCF para exportación a Brasil y 1.0 TCF para el mercado interno.

Hace cinco años Bolivia tenía demasiado gas y pocos mercados. Sin embargo en esa época en la región se perfilaba un proceso franco y proactivo de integración energética, como resultado lógico de las asimetrías regionales en términos de disponibilidad de hidrocarburos en algunos países y de creciente demanda de energía en otros.

Hoy, el país y la región enfrentan una situación diametralmente opuesta. Por un lado, la inversión en el sector se encuentra literalmente estancada, reducida a su mínima expresión, puesto que su capacidad de producción esta al límite y sobrecomprometida, y sus reservas apenas son suficientes para cubrir los compromisos, internos y externos, que ha asumido en los últimos dos años; por el otro, los procesos de integración energética regional se encuentran paralizados o seriamente cuestionados por una creciente y hasta justificada desconfianza de los compradores hacia los proveedores.

En las seis décadas desde la creación de YPFB en 1936, la industria petrolera de Bolivia nunca había presenciado niveles de inversión dignos de mención y sus reservas de gas nunca habían pasado de los 6 TCF. Al ser un país primordialmente gasífero, el desarrollo de la industria había estado históricamente limitado por las necesidades del mercado interno y por la falta de mercados de destino para el gas natural. De pronto, en 1996, se había suscrito el contrato de exportación con Brasil y, para sustentarlo, se habían introducido condiciones atractivas para la inversión en el sector que permitieran incrementar las reservas hasta, ojalá, el nivel necesario para respaldar el nuevo contrato.

Entre 1996, año de promulgación de la nueva Ley 1689, de hidrocarburos, y 2002 Bolivia logró atraer más de 2,400 millones de dólares de inversión extranjera en exploración y producción, pasando de un total acumulado de los seis años anteriores de 669.6, millones de dólares a un total acumulado de 3.048,5 millones en los seis siguientes.

Sus reservas probadas y probables pasaron de 6.6 TCF en 1997 a 54.9 TCFs en 2002.

Entre 1996 y 2002 las exportaciones de gas natural se duplicaron, de 5.6 


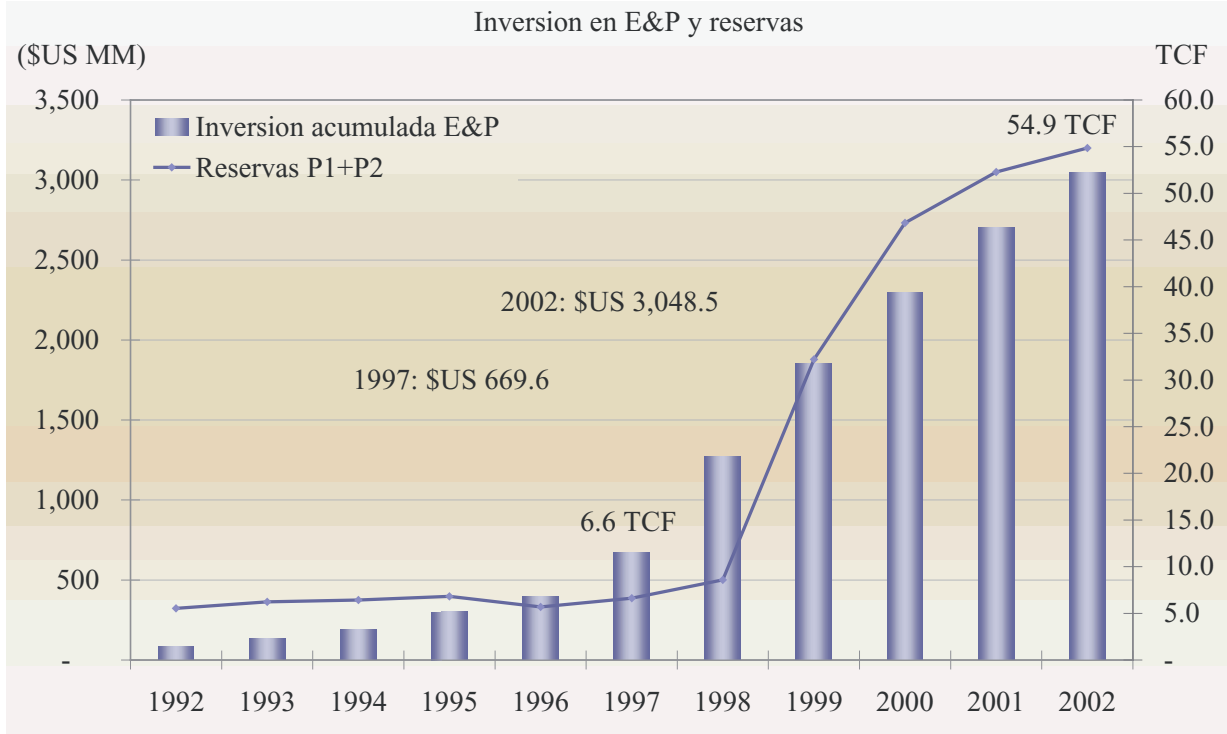

Exportaciones de gas

MMmcd

\$US MM

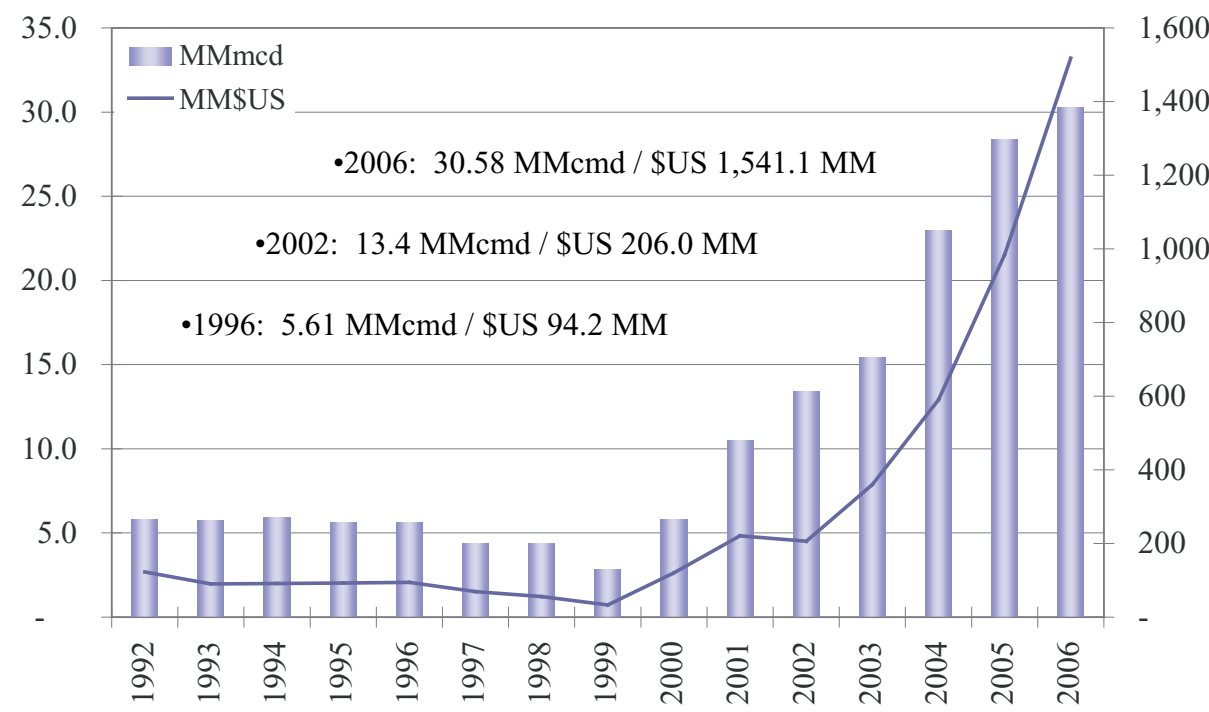


MMmcd y 94.2 millones de doláres a 13.4 MMmcd y 206 millones de dólares.

Gracias a una capacidad de producción en rápida expansión, al contrato de exportación suscrito en 1996 con Brasil, $\mathrm{y}$ a un incremento sostenido del precio del petróleo al que las exportaciones se encuentran indirectamente indexadas, esas exportaciones se duplicarían nuevamente hasta 2006, a 30.6 MMmcd y 1.541 millones de dólares.

Claramente, la «era del gas boliviano» y las perspectivas del sector eran brillantes, tanto así que se pensó que era lógico que, como lo había hecho con tanto éxito Trinidad y Tabago solo unos años antes, Bolivia explorara activamente la posibilidad de exportar gas natural líquido a los mercados de Norteamérica y que empezara a pensar en duplicar la capacidad del ducto de 30 MMmcd hacia Brasil.

Lamentablemente, a partir de la campaña electoral de 2002 el discurso político evolucionó hacia un contenido cada vez mas emotivo y nacionalista. Desde 2002 el gas se convirtió en el principal si no en el único tema de debate público, político y económico, y el «debate sobre el gas» terminó en la «guerra del gas», con el derrocamiento de un presidente en 2003, con el referéndum -o mas bien plebiscito- del gas convocado por Carlos Mesa en 2004, en una nueva Ley de hidrocarburos en 2005 y, finalmente, en la nacionalización del gas en 2006.

\section{El NUEVO RÉGIMEN}

Más allá del régimen fiscal resultante del proceso iniciado en 2004, los siguientes tres elementos del nuevo marco legal para el sector, introducidos a partir de la Ley 3058 de mayo de 2005 , constituyen los tres pilares fundamentales del nuevo régimen del gas. Su tono y su contenido reflejan un alto contenido político e ideológico.

Primero, la propiedad estatal establecida en la nueva ley, ya no de los yacimientos o reservas de hidrocarburos, sino de la producción misma:

Ley 3058, ARTÍCULO $16^{\circ}$ (Propiedad de los Hidrocarburos)... El Titular de un Contrato de Producción Compartida, Operación o Asociación está obligado a entregar al Estado, la totalidad de los Hidrocarburos producidos en los términos contractuales que sean establecidos por éste.

DS 28701, ARTICULO 2.I. A partir del 1 de mayo del 2006, las empresas petroleras ... están obligadas a entregar en propiedad a Yacimientos Petroliferos Fiscales Bolivianos YPFB, toda la producción de hidrocarburos

Segundo, el absoluto control estatal sobre las condiciones, plazos, volúmenes y precios de exploración, explotación y comercialización interna y externa de los hidrocarburos:

Ley 3058, ARTÍCULO $86^{\circ}$ YPFB será el Agregador y/o Vendedor para toda exportación de Gas Natural, asignando los volúmenes requeridos a las empresas productoras...

2. Las Empresas Productoras que 
obtengan mercados de exportación por negociación directa, establecerán con YPFB la asignación de volúmenes para la agregación.

DS 28701, II. YPFB, a nombre y en representación del Estado, en ejercicio pleno de la propiedad de todos los hidrocarburos producidos en el país, asume su comercialización, definiendo las condiciones, volúmenes y precios tanto para el mercado interno, como para la exportación y la industrialización

Contrato de Operación Arts. 6.5 y 7.4 El Titular deberá presentar a YPFB para su aprobación los Programas de Trabajo y Presupuestos anuales... el Titular podrá realizar cambios al Programa de Trabajo y Presupuesto aprobados, siempre que cuente con la aprobación previa a dichos cambios por parte de YPFB; el Titular deberá presentar a YPFB, para su aprobación, un Plan de Desarrollo del o los Campos...

Tercero, lo que el gobierno boliviano ha venido a llamar el «control social» sobre este sector estratégico a través del otorgamiento por ley, a comunidades y pueblos campesinos, indígenas y originarios, de lo que en términos prácticos equivale a un veto sobre cada fase de la cadena de exploración y desarrollo de los hidrocarburos, y que introduce un serio riesgo de enfrentar exacciones arbitrarias por parte de comunidades originarias o campesinas en cualquier fase del negocio por la que puedan sentirse «afectadas».

Ley 3058, ARTÍCULO $114^{\circ}$ (Ámbito de Aplicación). En cumplimiento a los Artículos $4^{\circ}, 5^{\circ}, 6^{\circ}, 15^{\circ}$ y $18^{\circ} \mathrm{del}$ Convenio 169 de la OIT, ratificado por Ley de la República $N^{\circ} 1257$, de
11 de julio de 1991, las comunidades y pueblos campesinos, indígenas y originarios, independientemente de su tipo de organización deberán ser consultados de manera previa, obligatoria y oportuna cuando se pretenda desarrollar cualquier actividad hidrocarburifera prevista en la presente Ley.

Ley 3058, ARTÍCULO $115^{\circ}$ (Consulta). En concordancia con los Artículos $6^{\circ}$ y $15^{\circ}$ del Convenio 169 de la OIT, la consulta se efectuará de buena fe,... para determinar en qué medida serían afectados y con la finalidad de llegar a un acuerdo o lograr el consentimiento de las Comunidades y los Pueblos Indígenas y Originarios.

Además, en términos de participación estatal y de la carga fiscal del negocio, según Van Meurs Associates, firma especializada en sistemas fiscales de la industria petrolera, "la exportación de gas a larga distancia apunta típicamente a un "government take» en el rango de 48\%-57\%». Sin embargo, el régimen para el gas boliviano actual, cuyas exportaciones deben recorrer 2,400 Kms para llegar a la "city gate», por ejemplo, en Sao Paulo, aplica tasas del $65 \%-75 \%$ sobre ventas según el tamaño de los campos en explotación (ver gráfico al comienzo de la página siguiente). 


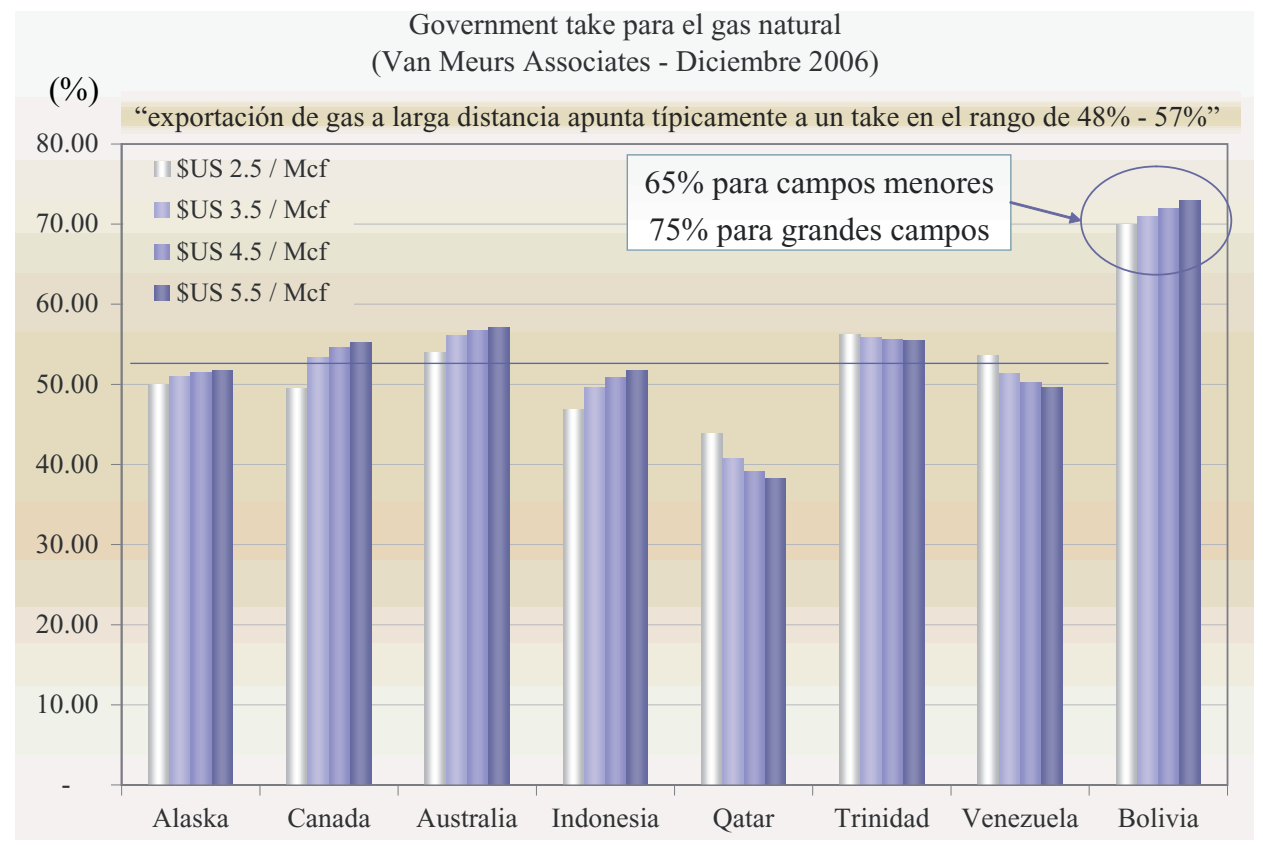

INCERTIDUMBRE Y AUSENCIA DE UNA POLÍTICA SECTORIAL DE ESTADO

A pesar de la firma de nuevos contratos de operación en octubre pasado, la incertidumbre continúa haciendo presa de las perspectivas de corto y mediano plazo de la industria petrolera y especialmente de sus inversiones, debido, entre otros, a:

\section{Marco legal}

- Retrasos en la protocolización de contratos desde octubre 29 de 2006, cuando fueron suscritos, hasta mayo 2 de 2007.

- Falta de clarificación y reglamentación de varios aspectos de la Ley 3058 relacionados con la operativización misma de las actividades de inversión y desarrollo.

- Los anuncios del propio gobierno sobre una próxima modificación de hasta 45 de los 144 artículos de la ley 3058.

- Los anuncios de «renegociación" de los 18 tratados bilaterales de inversión suscritos y ratificados por el país a partir de 1986 y el «retiro» de Bolivia del CIADI del Banco Mundial, lo que afecta drásticamente las garantías ofrecidas por el país a la inversión externa, cualquiera sea su origen.

- Las amenazas periódicas de rescisión de contratos «si las petroleras no invierten» y las condiciones de inseguridad jurídica derivadas de la prevalente ambivalencia, si no abierto antagonismo del gobierno para con la inversión externa y privada en el país. 
- Los resultados aún imprevisibles y la incertidumbre respecto de futuros lineamientos que la Asamblea Constituyente pueda imponer para la explotación de recursos naturales.

Continúa politización del sector

- Las anunciadas elecciones generales para 2008 y «el gas» todavía como inevitable elemento e instrumento de campaña proselitista.

- Las crecientes demandas de sectores radicales por que se realice una nacionalización «auténtica».

- La creciente inseguridad física de los campos productores y de las válvulas de paso de los ductos, que se ha convertido en instrumento de presión política de cualquier grupo y por cualquier motivo.

Impedimentos operativos

- La aún pendiente concreción de Acuerdos de Entrega y Planes de Desarrollo que se encuentran «en negociación».

- La discrecionalidad otorgada a YPFB de autorizar o no los planes de inversión, desarrollo y operación de los yacimientos.

- La creciente percepción de que YPFB comprobadamente está sujeto a la ingerencia política y además, de que es técnica y operativamente deficiente.

- El riesgo de contratos de exploración que en caso de un descubrimiento comercial están sujetos a previa aprobación parlamentaria de los contratos de explotación pertinentes.
- Actividades de exploración, desarrollo y transporte sujetas a veto originario/campesino.

Limitantes comerciales

- Reservas de gas oficialmente desconocidas (la última certificación data de 2004), lo que limita la capacidad y seriedad del país para comprometer nuevas exportaciones.

- Capacidad de transporte al limite $y$, en el caso del mercado interno, insuficiente.

- Imposición de lo que en términos prácticos equivale a un subsidio del petróleo y, ahora, del gas natural para el mercado interno que, entre otros, desincentiva la inversión.

- Incertidumbre respecto de la Exportación a la Argentina, principal motivación para la firma de contratos, a causa, entre otros, de la anunciada instalación de dos plantas de regasificación de GNL en las cercanías de Buenos Aires y otras dos en Chile (sin contar con dos ya en construcción y una tercera anunciada en Brasil).

- Existencia de un precio político mínimo para la exportación de gas natural de 5.00 dólares por MMBtu en frontera, que no considera ni distancias ni costos de transporte y que le resta competitividad en los mercados de destino.

- Perdida de credibilidad / confiabilidad de Bolivia como proveedor energético regional. 


\section{SituAción ACTUAL DEL SECTOR}

La incertidumbre, la inestabilidad y la inseguridad jurídica no son condiciones ideales para impulsar el crecimiento, la inversión ni la proyección nacional e internacional de una industria. Y estas se constituyeron en el marco fundamental de actividad de la industria petrolera nacional a lo largo de 2006 y en lo que va de 2007, a pesar de las favorables condiciones y oportunidades externas de que goza a nivel internacional.

Mientras que la inversión petrolera en la región mostró claras señales de reactivación durante 2006, especialmente en Perú, Argentina y Brasil, en Bolivia, la actividad petrolera, la inversión urgentemente requerida, los planes de reactivación y la consolidación de perspectivas comerciales claras para la industria se vieron seriamente afectados por los aprestos nacionalizadores, por la inseguridad jurídica y por la incertidumbre generada en el país por las posibilidades de modificaciones profundas a la política sectorial, al marco legal y regulatorio de los hidrocarburos y por las perspectivas, poco claras a pesar de la suscripción de los nuevos contratos de operación en octubre pasado, de crecimiento y sostenibilidad futura del sector.

Las inversiones en exploración y producción petrolera en el país han disminuido de manera alarmante en los últimos cinco años y se mantienen en niveles reducidos en espera de lineamientos definitivos en el marco sociopolítico, económico y petrolero. Dichas inversiones son urgentemente necesarias para que Bolivia esté en condiciones de sustentar nuevos contratos de industrialización o de exportación de gas natural, incluido el de Argentina, en vista de las serias limitaciones actuales de la capacidad de producción y entrega de gas del sistema y de las crecientes dudas sobre la suficiencia de las reservas, cuya última certificación data de hace casi tres años.

La actual situación y las perspectivas de reactivación de la industria petrolera en Bolivia deberían ser materia de seria preocupación, entre otras razones, debido a que:

- La inversión en el sector petrolero en las últimas dos administraciones. (198 millones de dólares en 2006 y 49.8 millones de dólares a abril de 2007 , último dato oficialmente disponible) se encuentra entre los niveles más bajos de la última década y no son ni mínimamente comparables con los alcanzados entre 1998 y 1999, de 600 millones de dólares anuales (ver gráfico 1 en la siguiente página).

- El número de pozos perforados en Bolivia durante la gestión 2006 y en lo que va de 2007 no llega a los 10 anuales, lo que contrasta marcadamente con los 64-65 pozos que se perforaron anualmente entre 1998 y 2000 , los 1594 pozos perforados en Argentina en 2006, los 230 en Brasil, los 241 en Colombia o los 85 en Perú (ver gráfico 2 en la siguiente página).

- El número de equipos de perforación en actividad en el país también 


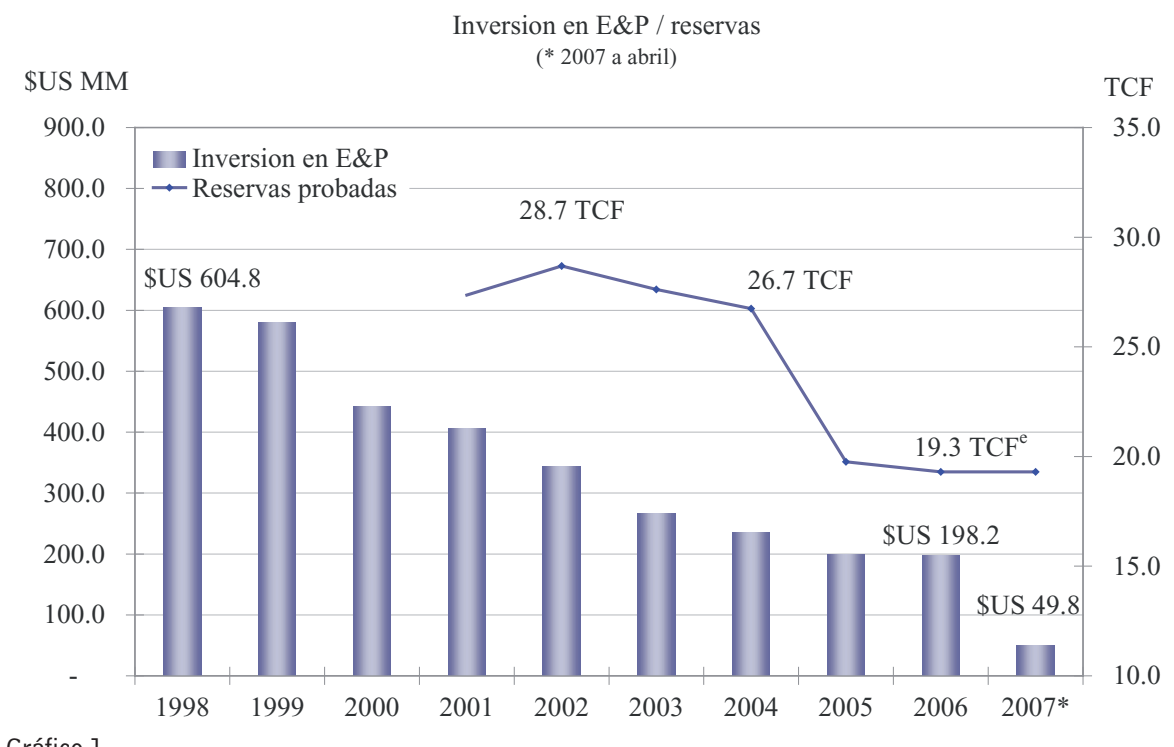

Gráfico 1

Pozos perforados: 1998 - 2006

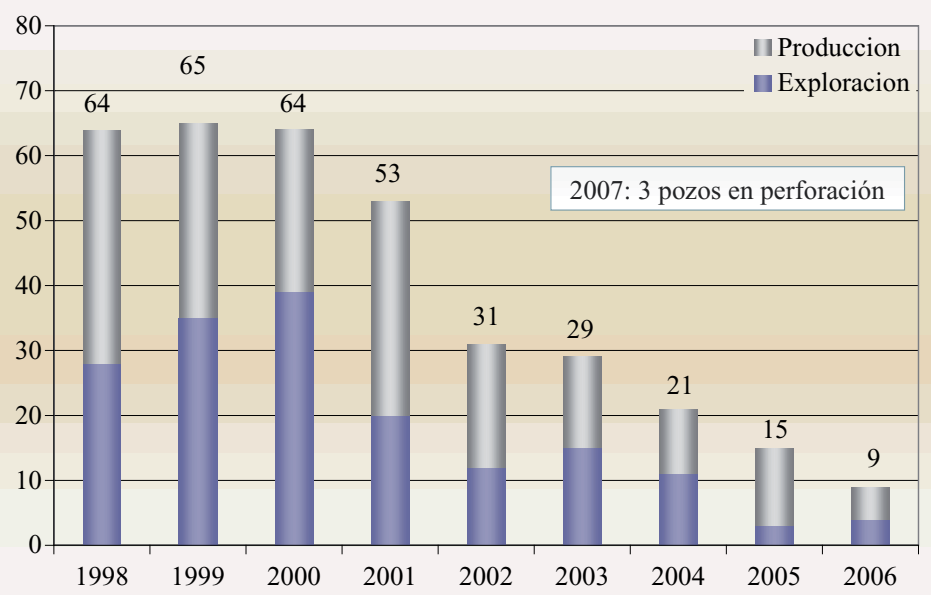

Gráfico 2 
ha caído a niveles mínimos, más compatibles, nuevamente, con intenciones de mantener los actuales niveles de producción que con cualquier previsión para siquiera empezar a incrementarlos en algún momento. En lo que va de
2007 no pasan de tres, mientras que a la fecha el número de equipos de perforación en Argentina son 85, en Brasil 36, en México 84, en Venezuela 73 e inclusive en Perú, 9.

(Ene 1996 - Ene 2007)

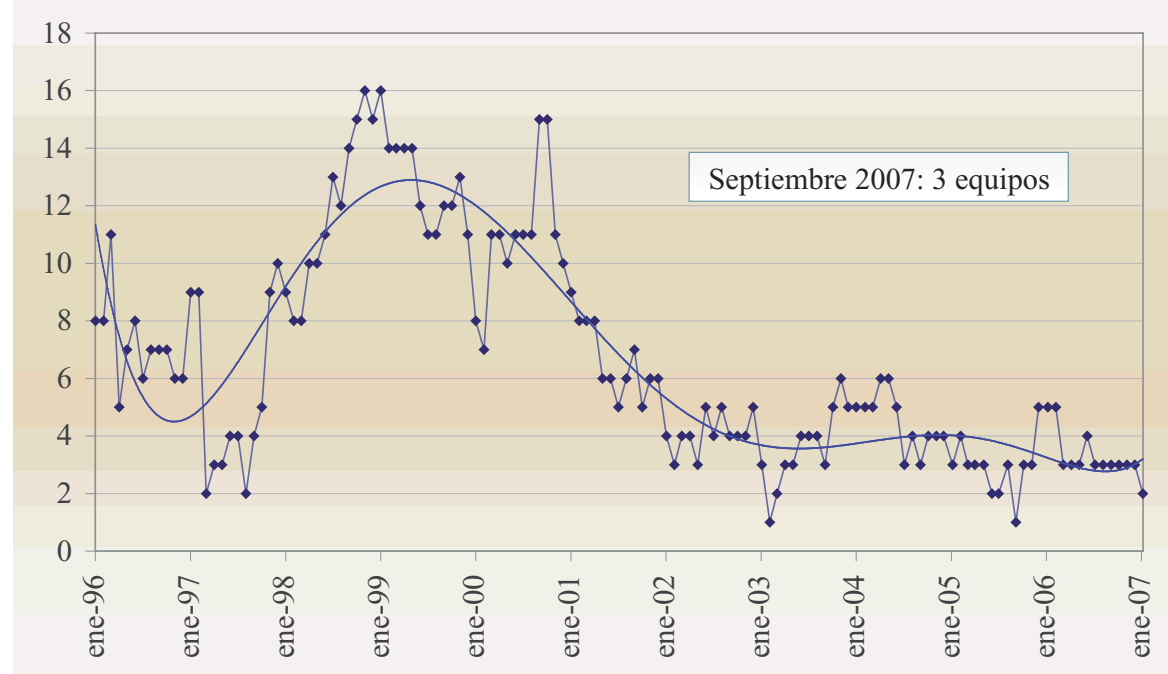

Gráfico 3

- Debido a la falta de inversión, la capacidad de producción de gas natural, se encuentra significativamente por debajo de los compromisos contractuales existentes asumidos por el país y ni qué decir de los nuevos compromisos asumidos recientemente, como ser el incremento de exportaciones de gas a la Argentina hasta los 27.7 MMmcd a partir de 2010 o la provisión de otros 8 MMmcd para el proyecto metalúrgico del Mutún a partir de 2011.

En el último mes, Brasil ha requerido $30 \mathrm{MMmcd}$, lo que ha implicado que
Bolivia se vea obligada a suspender totalmente los envíos a la termoeléctrica de Cuiabá y a suspender el contrato de BG Bolivia con Comgas, lo que confirma fehacientemente que el país no cuenta con la capacidad suficiente de entrega de gas natural para cumplir con sus actuales compromisos.

Se estima que en 2007 el volumen promedio de gas natural disponible para entrega habrá aumentado solo marginalmente, a alrededor de 36.6 MMmcd a partir de los 35.5 MMmcd obtenidos en 2006. 
De mantenerse esta situación, que es lo más probable según lo ha reconocido el propio gobierno al menos para el corto plazo, la capacidad de producción de Bolivia ya estaría casi $10 \mathrm{MMmcd}$ por debajo de los compromisos contractua- les diarios existentes. Y de concretarse todos los compromisos asumidos recientemente por el gobierno, a partir de 2010 Bolivia podría enfrentar un déficit insostenible de producción de 37.6 MMmcd.

Gas natural: volumenes de entrega

(MMmcd)

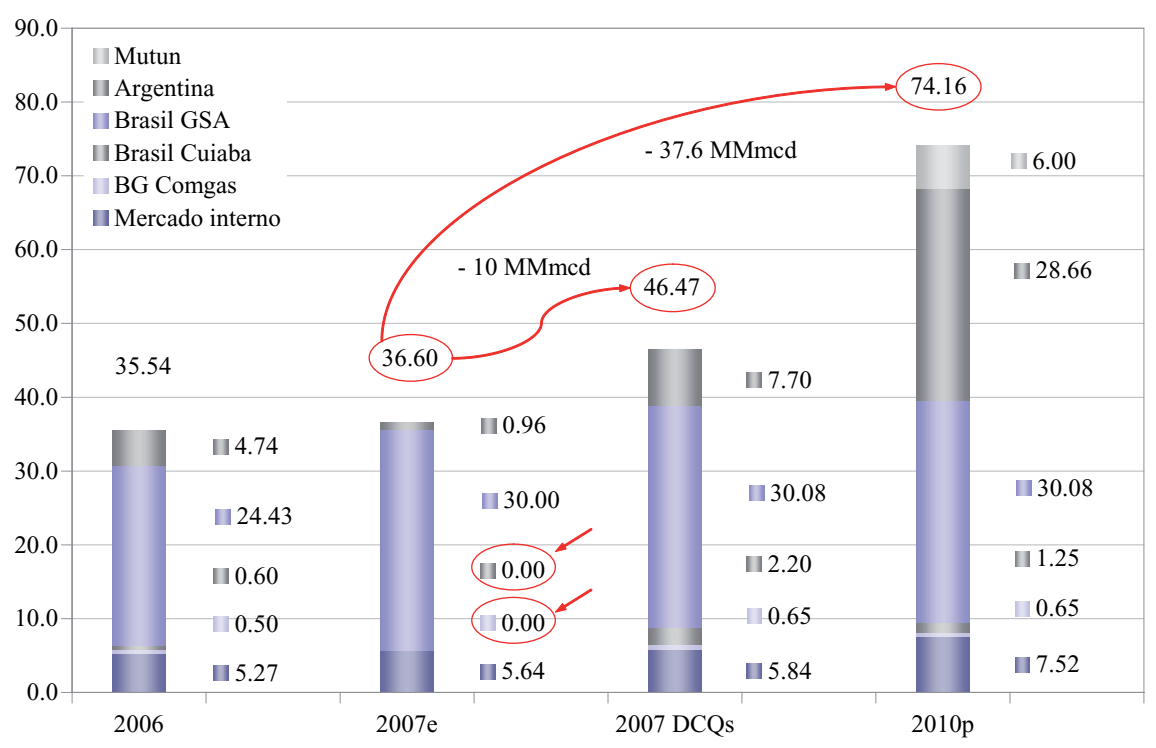

- De concretarse todos los acuerdos y compromisos asumidos, incluidos los 27.7 MMmcd para la Argentina y los 8 MMmcd para el proyecto siderúrgico del Mutún a partir de 2010, en ese momento Bolivia ya no dispondría de reservas probadas suficientes para cumplirlos. A la fecha, estas reservas se encontrarían en 19,3 TCF «según revelan informes oficiales procesados por el Ministerio de Hidrocarburos y Energía y refrendados por YPFB para el período enero de 2007, debido, principalmente, a nuevas

perforaciones en los campos delimitando su área productora y la reducción en el factor de recuperación debido a que los cálculos realizados estaban en función a las propiedades de los fluidos, y no así al avance del acuífero en estos campos» ${ }^{1}$.

En 2010 Bolivia deberá literalmente duplicar su capacidad de producción,

1 Energy Press, Edición 350 - 25/06/2007, «El gas y el petróleo duermen, Oficial: las reservas de gas han descendido a 19,3 TCFs». 


\begin{tabular}{|lcc|}
\multicolumn{3}{|c|}{$\begin{array}{c}\text { Reservas comprometidas } \\
\text { (TCF) }\end{array}$} \\
\hline & MMmcd & $\begin{array}{c}\text { Reservas } \\
20 \text { años }\end{array}$ \\
\hline Interno (promedio) & 11.20 & 2.89 \\
\hline Brasil GSA & 30.08 & 7.75 \\
\hline Brasil Cuiaba & 2.20 & 0.57 \\
\hline Argentina GSA & 27.70 & 7.14 \\
\hline Mutun & 8.00 & 2.06 \\
\hline Total & 74.28 & 20.41 \\
\hline P1 reservas & & 19.30 \\
\hline
\end{tabular}

su capacidad de tratamiento en campos, su capacidad de transporte y su capacidad de compresión. La probabilidad de que el país pueda aumentae al doble su capacidad de entrega de gas en los próximos dos años -duplicando su capacidad de producción, de tratamiento y de transporte de los líquidos asociados que ello implica-, es a estas alturas sumamente dudosa, lo que podría obligar al país a solicitar una renegociación del contrato de exportación suscrito hace solo unos meses con el gobierno argentino y a abrirle una ventana política de oportunidad a Argentina de modificar sus plazos y condiciones.

Según estimaciones actuales, solo lidiar con los nuevos requerimientos de gas natural implicaría una inversión de 3.200 millones de dólares. Si se tratara de enfrentar además, el inevitable incremento de la producción asociada al gas natural, de alrededor de $50 \mathrm{mil}$ barriles de condensados y líquidos, la inversión requerida podría alcanzar los 7 mil millones de dólares. Y dicha inversión tendría que realizarse, si las condiciones internas estuvieran dadas mañana, en los próximos dos años (ver gráfico página siguiente).

Es poco probable que en las actuales condiciones se pueda dar una reactivación real de la industria petrolera en el país. En todo caso, puede decirse que más allá de los anuncios -y los anuncios son baratos-, en este momento no existe ningún indicio concreto de una reactivación de la inversión, de la perforación de pozos, de la contratación de nuevos equipos y, por lo tanto, de algún incremento de la producción a corto plazo.

La falta de competitividad del régimen tributario boliviano hace que las inversiones fluyan preferentemente a otros destinos, como ser Perú y Brasil, y la falta de competitividad relativa del precio del gas boliviano, que lejos de cualquier consideración técnica o comercial se ha impuesto de manera dogmática en el país, hace que Brasil y Chile estén hoy en proceso de comprometer sus mercados a la importación de LNG que, aunque a precios marginalmente superiores, evita cualquier dependencia 
2006 - 2010: gas natural de la A a la B

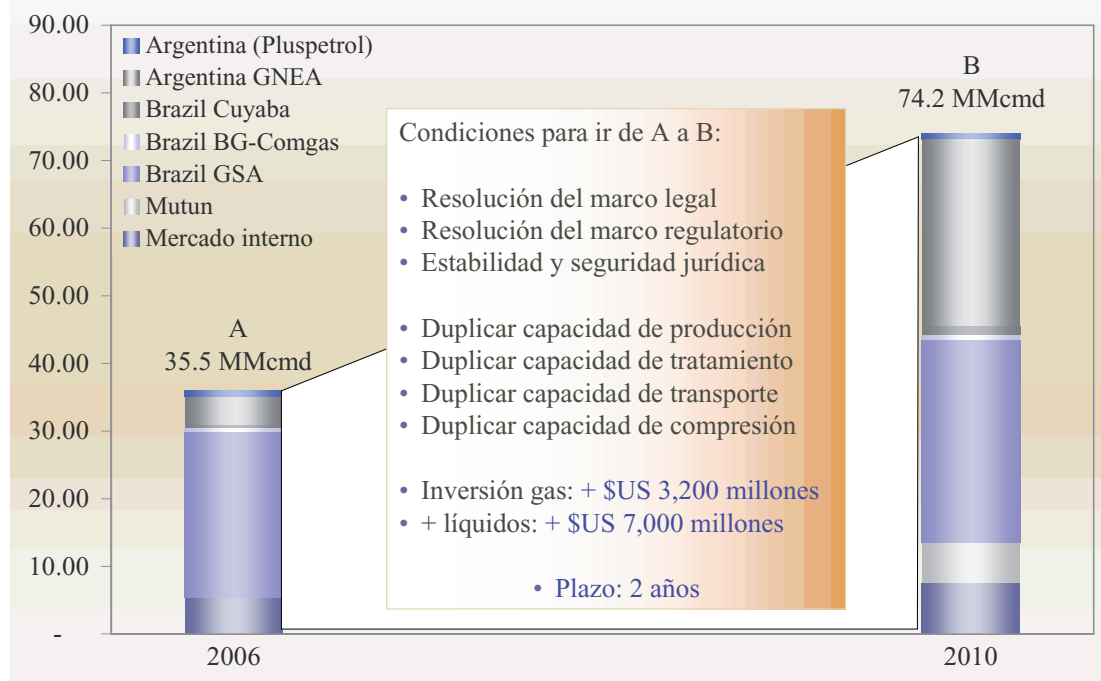

de Bolivia y asegura un abastecimiento confiable, flexible y alejado de los vaivenes y de la incertidumbre que hoy predominan en el país. La suma de los proyectos de regasificación de LNG en construcción o en consideración en el Cono Sur alcanza actualmente a los $50 \mathrm{MMmcd}$ que, por definición, son $50 \mathrm{MMmcd}$ de mercado para el gas boliviano que ya no serán requeridos en el largo plazo.

En resumen: por un lado, la negativa de Bolivia de insertarse oportunamente a los mercados mundiales de LNG ha sometido al país a una dependencia poco conveniente de los mercados regionales. Por el otro, las políticas adoptadas en Bolivia y sus negativas consecuencias en términos de inversión, de competitividad tributaria y comercial, y de confiabilidad han sido el factor crucial para impulsar y consolidar la llegada del LNG a los principales mercados potenciales para el gas natural boliviano en la región.

Ello debe llevar al país a sopesar la permanencia en el tiempo tanto de las oportunidades de comercialización actualmente disponibles en la región como de las favorables condiciones coyunturales de precio del petróleo y del gas natural reinantes a nivel internacional. La acelerada reactivación de la actividad petrolera en Argentina, los esfuerzos de Brasil por alcanzar su ya anunciada autosuficiencia en petróleo y, ahora, en gas natural, mediante masivas inversiones en exploración en su propio territorio y de la instalación de plantas de regasificación de GNL -al igual que en Chile y Argentina- deben ser motivo de preocupación en Bolivia, especialmente en vista de las autolimitaciones y trabas que se ha impuesto el propio país por razones ajenas al desarrollo y proyección de su industria gasífera en 
términos de sus esfuerzos futuros por consolidar otros mercados para el gas natural boliviano, como ser el de Chile y, a través del LNG, los de la cuenca del Pacífico.

La suscripción de nuevos contratos de explotación y las perspectivas de mercado en Argentina permiten efectivamente percibir una luz al final del túnel para la reactivación de la actividad petrolera de Bolivia. Sin embargo, estos elementos deben necesariamente acompañarse de un ambiente propicio para las inversiones en lo que respecta a competitividad, estabilidad, certidumbre y seguridad jurídica, que aún no llegan a vislumbrarse en el país.

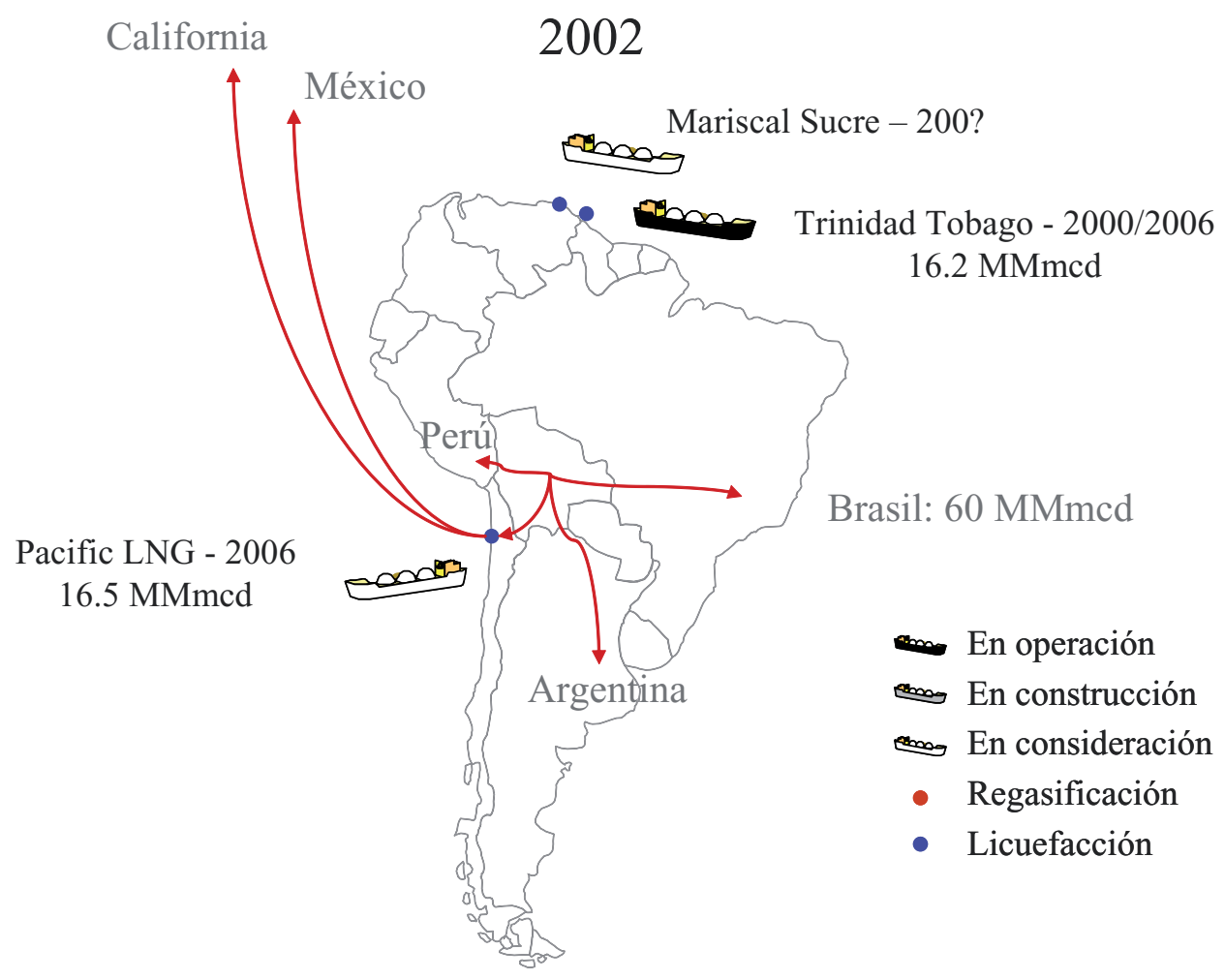




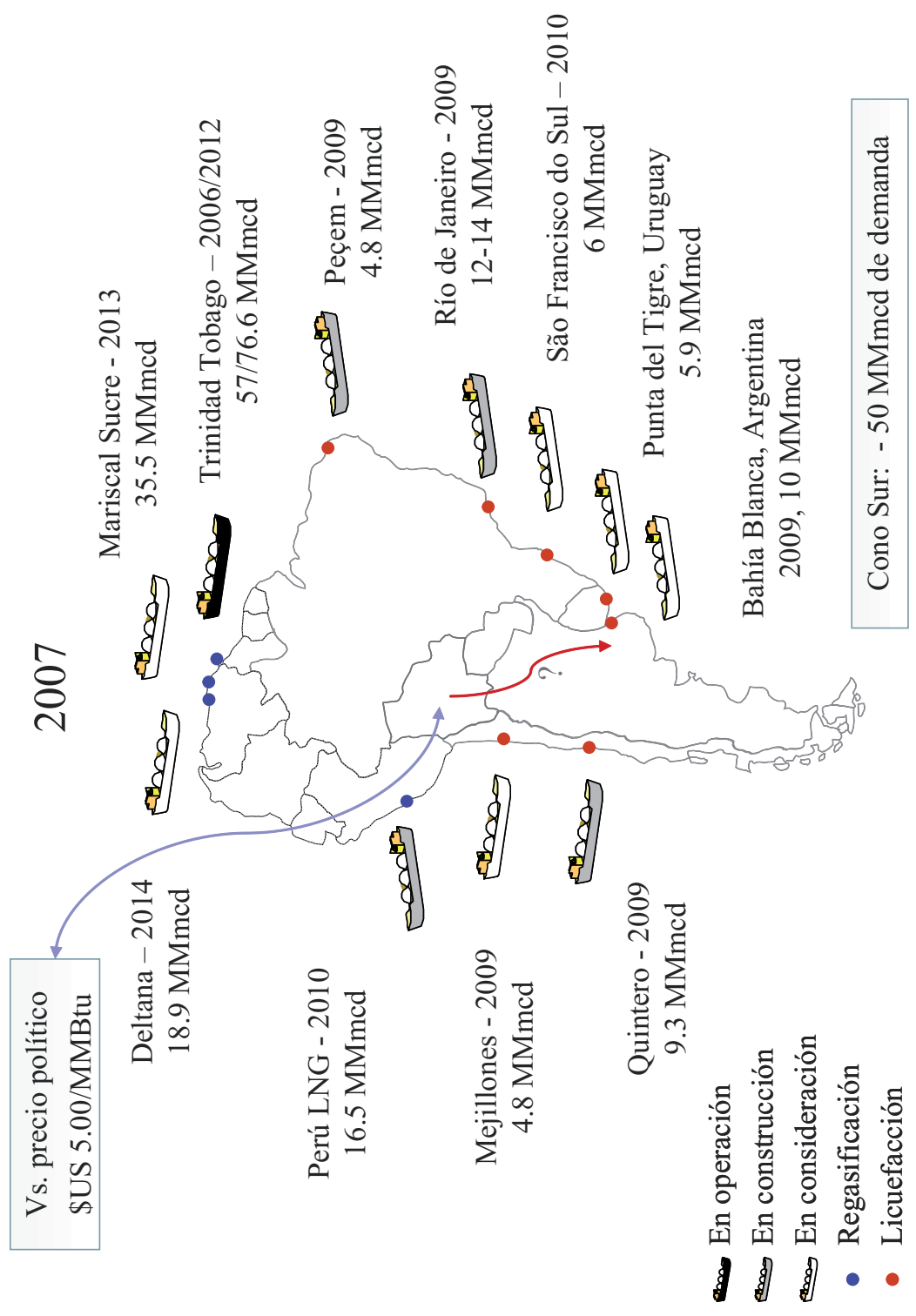

